\title{
Inovação tecnológica e inovação narrativa: caminhos para o design no polo moveleiro de Ubá
}

Technological innovation and narrative innovation: paths for design

in the furniture industry of Ubá

L'innovation technologique et l'innovation narrative: les

alternativesde design pour l'industrie du meuble d'Ubá

La innovación tecnológica y la innovación narrativa: alternativas para el

diseño en la industria del mueble de Ubá

\author{
Maria Luiza A. C. de Castro* \\ Juliana Cardoso**
}

Recebido em 3/5/2010; revisado e aprovado em 25/6/2010; aceito em 30/6/2010

\begin{abstract}
Resumo: O polo moveleiro de Ubá tem apresentado um grande desenvolvimento econômico nos últimos anos. Entretanto, a análise da produção local revela que não existe uma diferenciação pelo design, e que a competitividade é baseada na diminuição do custo. As propostas que têm sido feitas para reposicionamento do polo e conquista de mercados mais exigentes vão demandar, portanto, a construção de novas estratégias em design, para que ele possa se tornar um elemento de distinção da produção local.

Palavras-chave: Polo moveleiro de Ubá. Design. Políticas públicas.
\end{abstract}

Abstract: The furniture industry of Ubá has presented a major economic development in recent years. However, the analysis of the local production shows that there is no differentiation through design and competitiveness has been based on lower costs. The proposals that have been made to reposition the local production and conquer more demanding markets will ask for the development of new strategies in design, so that it can become a distinctive element in the local production.

Key-words: Ubá's furniture cluster. Design. Public policies.

Résumé: L'industrie du meuble de Ubá a présenté un important développement économique ces dernières années. Toutefois, l'analyse de la produciton locale revèle qu'il n'y a pas de différenciation fondée sur le design, et que la compétitivité est basée sur une réduction des coûts. Les propositions qui ont été faites pour replacer la production et remporter les marchés les plus exigeants demandent, par conséquent, le développement de nouvelles stratégies en matière de design, de sorte qu'il puisse devenir un élément distinctif de la production locale.

Mots-clés: Industrie du meuble de Ubá. Design. Politiques publiques.

Resumen: La industria del mueble de Ubá ha presentado un importante desarrollo económico en los últimos años. Sin embargo, el análisis de la producción local demuestra que no existe una diferenciación de design, y que la competitividad se ha basado en costos más bajos. Las propuestas que se han hecho para cambiar la posición de la producción y ganar los mercados más exigentes pedirá para el desarrollo de nuevas estrategias en el design, de modo que pueda convertirse en un elemento distintivo de la producción local.

Palabras clave: Industria del mueble de Ubá. Design. Políticas públicas.

\section{Introdução}

O polo moveleiro de Ubá tem apresentado um grande desenvolvimento econômico nos últimos anos e, entre as atividades de apoio à organização produtiva, as instituições que atuam na região empreenderam algumas ações no sentido de promover o design. Esta preocupação institucional com o design partiu de diretrizes de políticas públicas nacionais, com o suporte do SEBRAE e SENAI, mas também de universidades e organizações com atuação regional. As intervenções buscaram reverter uma tradição de cópia de modelos e o tratamento da questão foi mais intenso entre 2004 e 2007, ficando, em anos mais recentes, a cargo das próprias empresas, que têm adotado direcionamentos individualizados. A análise da produção local revela, entretanto, que embora tenha havido uma grande evolução na qualidade dos móveis locais, não existe uma diferenciação baseada no design, mas apenas um nivelamento com o padrão nacional.

\footnotetext{
* Professora Doutora da Escola de Arquitetura e Urbanismo da Universidade Federal de Minas Gerais. E-mail: luiza@pattrol.com.br

** Mestranda; professora da Faculdade de Arquitetura, Urbanismo e Design da Universidade Federal de Uberlândia. E-mail: cardosodesign@yahoo.com.br
} 
Este artigo procura investigar os direcionamentos possíveis para intervenções institucionais de promoção do design, a partir de uma visão ampliada do contexto do polo. A primeira seção analisa a situação do polo, incluindo aspectos tais como a sua evolução; as características das empresas, sua produtividade, inovações tecnológicas e problemas enfrentados, os canais de comercialização e acesso ao mercado, a infraestrutura de que dispõe e suas relações de governança. A segunda seção acompanha as intervenções de instituições visando a promoção do design. A terceira seção investiga a coerência destas intervenções dentro do contexto das relações com os mercados nos últimos anos e procura identificar direcionamentos emergentes.

\section{Institucionalização do polo: as condições para o desenvolvimento}

O polo de Ubá é localizado na Zona da Mata Mineira e reúne nove municípios da região. A atividade moveleira surgiu como opção econômica à agricultura, a partir da perda da qualidade do fumo aí cultivado na década de 1960, iniciando-se, nesta ocasião, a fabricação de móveis residenciais em série para as classes sociais $C$ e D. A partir da década de 1970, com a falência da Dolmani, uma das empresas pioneiras, houve a fundação de vários outros estabelecimentos pelos antigos funcionários. A evolução do setor possibilitou a ampliação do número de empresas, que passou de 25 , em 1970, a 360, em meados da década de 2000 .

A atividade se estruturou melhor a partir da criação do Sindicato Intermunicipal das Indústrias de Marcenaria de Ubá INTERSIND em 1989, que teve ação importante no processo de institucionalização do polo. Outro importante marco institucional foi a criação do Movimento Empresarial, associação de dezessete indústrias moveleiras, que permitiu a construção de um pavilhão de exposições para atender à demanda do polo, no qual se organizam, desde 1994, duas feiras, a FEMUR - Feira de Móveis e a FEMAP - Feira de Máquinas, possibilitando a ampliação dos contatos comerciais, tanto com fornecedores como com compradores (SANTOS; CROCCO; SIMÕES, 2002).
O Balcão SEBRAE instalou-se em Ubá em 1995 e diversos programas e agências foram, desde então, estruturados para articular o desenvolvimento do polo. Em 2001, o SEBRAE implantou, na região, a metodologia do Adensamento da Cadeia Produtiva e, em 2002, iniciou-se o trabalho de organização do Arranjo Produtivo moveleiro que, a partir de 2004, passou a ser acompanhado pelo GEOR - Gestão Estratégica Orientada para Resultados, sendo incluído no grupo do projeto piloto de onze APLs (Arranjos Produtivos Locais) do GPT APL - Grupo de Trabalho Permanente para Arranjos Produtivos Locais.

O polo é composto, em sua maioria, por micro ou pequenas empresas, em geral, familiares, de capital fechado e $100 \%$ nacional, embora abrigue, também, a maior empresa de móveis de aço da América Latina Itatiaia, e de três outras empresas de grande porte. Atualmente, as 360 empresas moveleiras da região são responsáveis por aproximadamente 11.600 empregos diretos, e por grande parte das arrecadações municipais. O elevado índice de concentração (IC) da atividade nos municípios demonstra a forte especialização da economia local.

A baixa qualificação profissional leva, entretanto, a uma grande concentração de trabalhadores do setor em uma faixa salarial pequena, aparecendo como um dos grandes desafios ao desenvolvimento das empresas. A ação institucional tem tentado sanar o problema, mas a grande rotatividade faz com que as empresas, em geral, não se interessem em investir na melhoria do nível educacional, nem na qualificação de sua mão-de-obra (VALE, 2006).

O setor está estruturado de forma verticalizada, havendo, portanto, poucos encadeamentos produtivos intrassetoriais. Apesar da evolução em diversos sentidos, ele continua a caracterizar-se pelo baixo grau de especialização, com grande parte das empresas produzindo uma mesma linha de móveis e competindo entre si, principalmente através do mecanismo de preços.

As parcerias ocorrem esporadicamente e, principalmente, na organização de fretes e transporte ou compras de insumos. A existência de arranjos formais entre as firmas é bastante recente e limita-se a um gru- 
po de empresas líderes. Um número significativo de fabricantes mantém frota própria para transporte de mercadoria e as centrais de frete são utilizadas unicamente para as "pontas" de produção. A terceirização não é uma prática frequente e não se observa uma tendência no sentido de intensificação das parcerias (SILVA, 2008).

O polo vem passando, entretanto, por um processo de atualização tecnológica, possibilitado pelos resultados positivos das empresas e pela melhoria das condições de crédito, com um consequente aumento da produtividade e de vendas. A infraestrutura produtiva de uma grande parte das empresas é hoje completamente automatizada e informatizada. O aumento da produtividade é, também, resultado de processos de organização interna das empresas que procuram a redução de custos, a otimização do tempo de produção e o aperfeiçoamento tecnológico.

Constata-se, entretanto, a existência de sérios problemas de logística, devido à má condição das estradas, principalmente nas ligações para Belo Horizonte e Juiz de Fora, apesar dos investimentos recentes do governo no anel viário de Ubá. Esse fator tem se constituído como um entrave à atividade, pois é responsável, entre outros, por um prazo de entrega excessivamente longo.

O APL conta com o apoio de diversas instituições e programas no âmbito federal e estadual que visam prover apoio para a sua estruturação e fortalecimento, não tendo, porém, atuação garantida. Apesar de toda uma mobilização institucional, observa-se que apenas cerca de $20 \%$ das empresas estão envolvidas nas ações coletivas organizadas, o que tem pouca expressividade para a dinâmica empresarial da região (ALMEIDA; MOURA, 2005).

A exceção são as ações de mercado: para o ano de 2008, no âmbito do PPA Plano Plurianual, foi articulado o Projeto Extensão Industrial Exportadora - PEIEx, promoção comercial de microempresas e empresas de pequeno e médio porte, e de pesquisa de mercado, com grande participação. A APEX-Brasil - Agência Brasileira de Promoção de Exportações e Investimentos, também desempenha um importante papel, organizando, por exemplo, o Projeto Comprador e promovendo feiras internacionais.
O polo conta com uma boa estrutura acadêmica, estando no foco de importantes centros de pesquisa, ligados a universidades de Viçosa, Belo Horizonte e, em menor escala, Lavras e Juiz de Fora que, apesar dos inconvenientes da distância, proporcionam grandes ganhos em termos de construção do conhecimento nas várias áreas ligadas à produção de móveis local: gestão, engenharia de produção, design, engenharia florestal, entre outros. Também existe um curso superior em design oferecido pela UEMG - Universidade Estadual de Minas Gerais, além do CEFET - Centro Federal de Educação Tecnológica, e uma escola do SENAI. A FINEP Financiadora de Estudos e Projetos - por sua vez, financia uma série de projetos que contribuem para o conhecimento científico na região.

Os mercados consumidores prioritários das empresas da região são as classes $C$ e D, mas algumas empresas têm ampliado seu foco para as classes A e B, predominando a venda de móveis residenciais, confeccionados com painéis, e a tendência é de uma diversificação das linhas. Os principais mercados para a produção incluem o próprio estado de Minas Gerais, o Rio de Janeiro e Espírito Santo.

A comercialização da produção se faz essencialmente por meio de quinhentos representantes que são, hoje, responsáveis por $85 \%$ das vendas. Os concorrentes nacionais das empresas do polo são outros reconhecidos polos moveleiros, como os da Grande São Paulo, Votuporanga e Mirassol, Caxias do Sul e Bento Gonçalves e, entre os concorrentes internacionais, destaca-se a China (VALE, 2006).

Desde o final da década de 1990, a exportação vem se organizando, tendo passado inicialmente por um processo de aprendizado, que foi estruturado por meio da formação de dois consórcios, com o apoio de instituições, mas também de empresas fornecedoras. Existem, hoje, cerca de vinte empresas exportadoras, mas somente uma média de $15 \%$ de sua produção é destinada à exportação. Os principais destinos são os países da América do Sul, EUA, México, Angola, África do Sul, Líbano e Qatar.

No que diz respeito às ações visando à sustentabilidade ambiental, a recente mobi- 
lização para o licenciamento ambiental das empresas foi precedida por reuniões de conscientização, mas, na maioria dos casos, limitou-se à obtenção do licenciamento, sem necessidade de planejamento ambiental, pelo fato de as empresas possuírem um máximo de $1000 \mathrm{~m}^{2}$ de área construída e oito funcionários. Além disso, não há cultura e consciência ambiental ou uma gestão ambiental integrada no polo e nem no setor, existindo, ainda, pouca divulgação do conhecimento existente em reciclagem e tratamento.

No que se refere ao uso de matéria-prima sustentável, a preocupação começa a se colocar, devido às dificuldades de obtenção de madeira oriunda das regiões Norte e Sul do país, fator que, aliado às restrições ambientais e legais, vem acarretando problemas de abastecimento e contínua elevação de preços. Neste sentido, alguns programas estão buscando a formação de uma base florestal estratégica para a criação de segmentos industriais, como serrarias, usinas de preservação, unidades de secagem e indústrias de painéis (aglomerado e MDF).

\section{Estratégias de design: aprimoramento tecnológico e promoção}

Crocco e Horácio (apud OLIVEIRA JR., 2002 , p. 17) constatavam, em 2001, que as empresas do polo, em sua maioria, não utilizavam mão-de-obra qualificada na criação de novos modelos para seus produtos, praticando em geral a imitação que era, inclusive, "muito bem aceita na região". O censo moveleiro (FEDERAÇÃO DAS INDÚSTRIAS DO ESTADO DE MINAS GERAIS, 2002, p. 35), por sua vez, identificava uma baixa prioridade para os "investimentos em design" (indicador de 28 em 100), embora muitos dos empresários afirmassem conhecer sua importância. Crocco e Horácio (2001) atribuíam o desinteresse pela questão da inovação de produto via design ao mercado consumidor do polo, predominantemente de classes C, D, cujo padrão de consumo não exige uma contínua inovação no estilo dos produtos.

Outro fator que restringia, nesta época, a inovação era a falta de interação entre o produtor do arranjo e seus consumidores: a interação que o censo moveleiro detectava se fazia, na verdade, por intermédio dos representantes. Crocco; Horácio (2001) entendiam que a falta de contato direto com os consumidores desestimulava os investimentos em design.

Embora as empresas em geral e algumas empresas líderes praticassem a imitação do produto, existiam, entretanto, entre as empresas líderes, algumas que desenvolviam inovações, visando lançar novos modelos no mercado.

Estes diagnósticos levaram a uma mobilização institucional para a implantação de design no polo, num momento que coincidiu com um processo de atualização tecnológica possibilitado pelos resultados positivos das empresas, pela melhoria das condições de crédito e pelo aumento da produtividade e de vendas.

A questão do design foi tratada inicialmente em reuniões e palestras promovidas pelas instituições, em meio à articulação do polo. A abordagem nas empresas foi efetivada também por meio de cursos promovidos pelo SENAI, nos quais se conjugou qualificação de mão-de-obra com sensibilização. Estes primeiros cursos/oficinas de design tiveram como público-alvo os encarregados ou funcionários indicados pela própria empresa, que passaram a exercer o papel de formadores de opinião no âmbito destas, buscando uma melhor inserção de design.

Em 2003/2004 foi articulado um primeiro programa de design envolvendo um maior número de instituições, o Pró-Design, do qual participaram a Universidade Federal de Viçosa, o Colégio Técnico Universitário e o Curso Técnico em Design de Móveis da UFJF, além de profissionais e estagiários de design e indústrias do Polo (SINDICATO INTERMUNICIPAL DAS INDÚSTRIAS DE MARCENARIA DA UBÁ, 2005). Assim, o treinamento Interativo Multidisciplinar de D esign para m óvelpossibilitou o desenvolvimento de projetos de mobiliário para as empresas do polo de Ubá e de outras localidades, que tiveram o apoio de equipes formadas por um aluno e dois técnicos. O programa teve o mérito de aproximar os alunos da realidade profissional, ao mesmo tempo em que proporcionou às empresas uma visão de design.

Mas foi em 2004 que ocorreu na região a maior mobilização em torno do design, 
com uma grande campanha para sua promoção, por meio da coleção Ubá Móveis de Minas. A ação, promovida pelo Via Design (SEBRAE), em parceria com a FIEMG/IEL/ SENAI e o INTERSIND, teve a participação de onze empresas, e onze designers (sob a coordenação da UEMG) (AGÊNCIA SEBRAE DE NOTÍCIAS, 2009) e levou a uma mudança da imagem do polo não só junto ao mercado, mas principalmente dentro do próprio polo.

O trabalho visou o desenvolvimento de peças variadas de mobiliário, procurando conjugar o uso de novas matérias-primas com o trabalho em maquinários e ferramentais já utilizadas pelas micro e pequenas empresas envolvidas. Foram utilizadas referências estético-formais com base no território, numa tentativa de decodificação da cultura local, para a inserção de identidade no produto, trabalho que teve o apoio de um antropologo (MORAES, 2008).

Os resultados incluíram uma coleção de peças - a "Coleção Ubá Móveis de Minas" - a criação da marca correspondente e de uma revista, publicada pelo INTERSIND em parceria como o Instituto Euvaldo Lodi - IEL (sistema FIEMG), além de proporcionar aos designers participantes a oportunidade de se preparar para o trabalho em ambiente de aglomerados produtivos. A coleção colocou-se principalmente como ferramenta de marketing para promoção do polo, ao tentar amenizar a imagem que ele então portava, vinculada à cópia de modelos e, ao mesmo tempo, aumentou a auto-estima do empresariado.

As empresas adquiriram uma visão sobre o processo de design, participando da inserção e desenvolvimento da metodologia; os móveis produzidos conferiram a elas visibilidade e permitiram a sua participação na estratégia de marketing, que incluiu a elaboração e distribuição do catálogo, bem como a exibição dos produtos em diversas feiras locais, estaduais e mesmo em outros estados.

Dentro de uma outra linha estratégica, em 2005/2006, foi desenvolvido o projeto "Fortalecimento do Polo Moveleiro de Ubá e Design Integrado: Desenvolvimento de Produtos para a Certificação". Com o objetivo de disseminar a prática do design junto às indústrias de móveis, o projeto propôs le- var os empresários a compreender o processo projetual para torná-los aptos a decidir o momento certo de sua adoção. Outro objetivo foi a padronização de processos e produtos com vistas à certificação para possibilitar a expansão do mercado e exportação (MARÇAL et al., 2006).

A metodologia adotada incluiu uma fase de protocolo de análise de qualidade, que identificou três grandes fontes de problemas na produção: gargalos de produção, improvisações no fluxo produtivo e defeitos/ retrabalhos. Em seguida, foram desenvolvidos workshops para as sete empresas participantes, para nivelamento de informações; por fim, a elaboração de um diagnóstico das necessidades e demandas das empresas permitiu o desenvolvimento de um produto para entrar em linha de produção para cada empresa, visando à certificação (MARÇAL et al., 2006). Uma equipe multidisciplinar foi responsável pela execução do projeto, incluindo profissionais e estagiários de engenharia de produção e de engenharia de estruturas da UFMG e uma equipe de profissionais e estagiários da Escola de design da UEMG. O projeto teve como mérito a realização de um levantamento de problemas produtivos e de questionamentos tecnológicos colocados aos empresários para reflexão como parte do processo de busca de eficácia e eficiência.

Ainda em 2005/2006, foi promovido pelo SENAI o Projeto "Design Dez" com objetivo de inserir o design nas empresas: dez alunos atuaram como consultores junto a dez empresas, sob coordenação do núcleo do SENAI. O projeto enfrentou, entretanto, dificuldades de ordem burocrática.

Além destes projetos, outro elemento importante para a criação do valor simbólico do design na região foi o Salão de Design, evento paralelo às feiras FEMUR e FEMAP, criado em 2003, pelo Núcleo de Inovação e Design em Mobiliário em parceria com SENAI, SEBRAE, INTERSIND e Movimento Empresarial. Tendo como objetivo incentivar e estimular a adoção de novas soluções e tecnologias no design, a sua promoção incluiu concursos regionais e nacionais de design e a exibição de peças selecionadas nos concursos ou desenvolvidas em atividades no polo, além de fóruns e palestras. A partir de 2008, entretanto, a atividade foi interrompida, 
devido, por um lado, a um conflito de interesses gerado com as empresas promotoras do evento e, por outro, à crise econômica (informação verbal $)^{1}$.

Nos últimos anos, o foco na articulação de estratégias de design não tem sido prioridade das instituições. Segundo Rossignoli, a grande mobilização para ações coletivas de design ocorreu entre 2004 e 2007, tendo essas ações, desde então, sido colocadas de lado. Considera-se, no polo, que não há necessidade de dar continuidade a este tipo de ação, uma vez que as empresas estão tratando a questão de forma individualizada, coerente com suas estratégias (informação verbal) ${ }^{2}$. Esta situação demanda, entretanto, uma análise mais detalhada.

\section{Direcionamentos projetados e tendências emergentes para o design no polo}

A observação dos produtos e dos seus processos de geração em Ubá demonstra que não existe espontaneidade na implantação de um design inovador, mesmo que haja uma procura de nivelamento com os padrões de referência do setor.

Embora pareça haver um movimento crescente no sentido de contratação de designers pelas empresas do polo, estes profissionais têm atuado de forma estritamente operacional, desenvolvendo produtos que acompanham as tendências dominantes, num processo de geração de projetos que, aos poucos, substitui a cópia adaptada pela imitação criativa - prática, aliás, generalizada na maioria dos polos moveleiros do Brasil.

As ações que procuram nivelar o design com o padrão nacional têm sido incorporadas às rotinas das empresas, mas existe uma resistência local ao desenvolvimento de produtos realmente inovadores. As tentativas institucionais de um direcionamento neste sentido não levaram ao sucesso comercial, pelo fato de os produtos terem custos mais elevados ou não se adequarem ao segmento de mercado alvo do polo. Portanto, o estímulo promovido pela existência de políticas públicas envolvendo atividades inovadoras de design - tais como os financiamentos e subvenções da inovação, a disponibilização de estrutura de pesquisa das universi- dades, bem como dos projetos apresentados por iniciativa de seus pesquisadores - têm sido subaproveitados.

A estrutura de decisão para as ações coletivas de design ainda é fragmentada, partindo da iniciativa das diversas instituições envolvidas. O SEBRAE, através do Via design, e o sistema SENAI/FIEMG/IEL, que exerceram em outros estados uma forte liderança na definição de atividades de promoção, suporte e educação em torno do design, em Ubá não têm tido um papel relevante na articulação coerente destas políticas. A atuação institucional tem o potencial de se reforçar, com a organização do Centro Mineiro de Design e do Centro de Estudos em Design da Madeira liderado pela UEMG, que reúne um grande número de entidades parceiras; não existem, entretanto, atualmente, planos definidos para uma intervenção destas entidades, mais focada em Ubá (CENTRO MINAS DESIGN, 2009). Segundo Rossignoli, as empresas têm preferido incorporar designers a seus quadros, em detrimento da utilização de serviços disponibilizados institucionalmente (informação verbal) ${ }^{3}$. Porém, o fato dos designers contratados serem jovens profissionais, muitas vezes de nível técnico, dificulta sua ação de uma forma mais estratégica dentro dos direcionamentos das empresas.

A condução das atividades coletivas de design em Ubá tem sido caracterizada pela falta de continuidade das ações e direcionamentos. Projetos como o Pró Design, o Pró Ubá, a Coleção Ubá Móveis de Minas e outros não tiveram sequência, apesar de sua relevância. Os responsáveis entrevistados atribuem este fato à resistência e desinteresse dos empresários com relação às ações, cujos custos parecem proporcionalmente altos quando comparados ao baixo retorno imediato. Rossignoli acredita que as ferramentas fornecidas pelas instituições têm sido utilizadas pelas empresas de acordo com suas estratégias individuais e que a incorporação do design tem ocorrido de forma gradativa e contínua, embora ainda incipiente (informação verbal) ${ }^{4}$. As estratégias coletivas, apesar de descontínuas, tiveram o mérito de despertar as empresas para a questão. Entretanto, vários empresários entrevistados confirmam o desinteresse pelas ações coletivas de design e contestam, ainda, o teor teórico das metodologias. 
No polo de Ubá, a sequência na qual as ações de design tem se inserido no conjunto de atividades de promoção do APL parece coerente, tendo sido precedidas por atividades de estruturação física e organizacional do polo, tais como investimentos em infraestrutura, modernização de maquinário, capacitação de mão-de-obra, fortalecimento de governança, entre outros.

As próprias atividades de design obedeceram a uma lógica, iniciando-se com os cursos e oficinas oferecidos pelo SENAI nos quais conjugou-se qualificação de mão-de-obra com sensibilização; seguidos pela elaboração da coleção Ubá Móveis de Minas atuando na construção de uma imagem mais favorável para o polo e pelo projeto Pró Ubá, que visava a adequação técnica dos produtos.

Embora as ações tenham sido de pequena abrangência mobilizando poucas empresas (as duas principais ações - a elaboração da coleção "Ubá Móveis de Minas" e o "Projeto Pró Ubá", mobilizaram respectivamente onze e sete empresas), a baixa intensidade das atividades é coerente com a pouca mobilização dos empresários e com a medida na qual as ações têm sido absorvidas.

Assim, a situação do design no polo parece coerente com seu desenvolvimento econômico: um design pouco diferenciado tem sido suficiente para garantir o crescimento das empresas, baseado principalmente na diminuição dos custos, graças à inovação tecnológica e ao aumento do mercado que prioriza o preço e a facilidade de pagamento, atribuindo pouca importância ao design.

Esta situação de crescimento está ligada ao grande aumento do poder aquisitivo das classes $\mathrm{C}$ e $\mathrm{D}$ nos últimos anos e à própria expansão da classe $C$, a partir da conjuntura nacional favorável; o que tem despertado o interesse dos principais fabricantes e varejistas de bens de consumo (SANTOS, 2007). O potencial da classe $C$ chegou a aproximadamente R\$ 226 bilhões anuais em 2000, após um crescimento no número de famílias. de 3,4 milhões entre 1992 e 2000 (SANTOS, 2007). Entre 2003 e 2006, o aumento foi de oito pontos percentuais (de $32 \%$ para $40 \%$ do total da população do país), devido à redução das classes D e E, (que passaram de $46 \%$ para $38 \%$ ) (DATAFOLHA, 2006).
O aumento no número de integrantes da Classe $\mathrm{C}$ e de seu poder aquisitivo é especialmente decisivo para a evolução do setor de mobiliário, uma vez que a maior aspiração de compra da Classe C são os móveis - que evoluíram de $31 \%$ para $37 \%$ na intenção de compra das famílias entre 2005 e 2007 (CETELEM/IPSOS, 2008).

Desta forma, o desenvolvimento da produção no polo de Ubá parece estar relacionado com o aumento do poder aquisitivo de seus mercados privilegiados, dentro de um contexto que tem se baseado na queda do custo, a partir da organização da infraestrutura, da atualização tecnológica e do aumento da escala de produção, bem como na possibilidade de exportação para mercados externos, com características análogas aos já conhecidos internamente - Chile, México, Angola, Panamá entre outros.

A busca da redução de custos é consistente com a conquista de uma grande participação no mercado, uma vez que tal busca permite melhores condições de compra, otimização dos custos de produção, distribuição e marketing, bem como vantagens financeiras, disponíveis para empresas maiores, (WRIGHT; KROLL; PARNELL, 2000). Neste sentido, o redesenho de produtos, que é a principal estratégia de design aplicada pelas empresas de Ubá, contribui para o aumento na escala de produção e melhorias, tais como a simplificação do projeto e redução de número de partes ou a utilização racional de matéria-prima permitem uma diminuição no tempo de fabricação.

O momento atual pelo qual passa o aglomerado tem, portanto, demandado que o design se alie à procura da eficiência produtiva por meio da padronização de processos, práticas e da redução de partes dos produtos, dando ênfase à reengenharia de processos e à produção, dentro de linhas de produção limitadas e menos sofisticadas. Os resultados econômicos da estratégia têm sido satisfatórios e não têm pressionado os empresários a se posicionar de forma mais criativa.

\section{Considerações finais}

O polo de Ubá tem se desenvolvido de forma destacada nos últimos anos, respondendo de forma competente ao crescimento 
de seus mercados principais. Algumas iniciativas institucionais têm procurado dar apoio ao design na região, mas a definição dos direcionamentos neste sentido tem partido principalmente das estratégias comerciais dos empreendedores, baseadas numa atualização tecnológica e nivelamento com os padrões de referência do setor.

Do ponto de vista econômico, esta estratégia tem se revelado eficaz para o polo, o que gera dificuldades para a inserção de um design mais inovador, que demandaria ações mais especializadas, um direcionamento estratégico menos evidente, com retorno financeiro mais incerto no curto prazo e com maiores possibilidades de erros de percurso, uma vez que baseada em valores mais abstratos. Desta forma, é natural que haja uma resistência dos empresários com visão imediatista em investir no design: enquanto persistir a conjuntura vigente, favorável ao desenvolvimento da produção de mobiliário de baixo custo, a relação custo/benefício do investimento em design inovador vai parecer aos empresários menos atrativa do que a de outros direcionamentos mais lucrativos. Assim, quando não existem resultados econômicos relevantes para a aplicação do design e ele não é reconhecido como um atributo que pode trazer benefícios econômicos e financeiros imediatos para as empresas, a sua aplicação tenderá a ser restrita. É necessário, entretanto, que as instituições supram a necessidade de uma visão de maior alcance e incitem a elaboração de cenários nos quais os direcionamentos de design tenham um enfoque mais baseado na criatividade, dando início a um processo de construção de competências neste sentido.

Não se trata de tentar impor o design aos empresários locais, mas de analisar a situação e encontrar estratégias adequadas para as circunstâncias observadas. O próprio questionamento interno que ocorre atualmente sobre o futuro do polo demonstra a necessidade de uma reestruturação de estratégias: em 2009, o SEBRAE Minas contratou a agência espanhola Competitiveness para realizar um diagnóstico do polo de Ubá e apresentar opções para o desenvolvimento de sua competitividade. Assim, novos cami- nhos estão sendo traçados para criar alternativas para uma evolução que, baseada até agora na redução do custo e aumento da demanda, pode vir num futuro próximo a atingir um ponto de saturação.

A proposta apresentada prevê a evolução do setor local por meio de uma tentativa estruturada, por um lado, pela tentativa de controle dos canais de venda e dos fornecedores e, por outro, pela oferta de produtos diferenciados, em busca de vantagens competitivas. Apesar de alguns aspectos desta proposta possibilitarem a ampliação das oportunidades de comercialização, ela envolve relações de subcontratação dentro do polo, que demandam um grande domínio de design por parte das empresas que vão comandar a cadeia. Porém, a produção local é, conforme, já visto, baseada em um acompanhamento de tendências e na utilização de um vocabulário estético já desgastado e pouco inovador. Em seu estágio atual, portanto, as competências de design no polo, ainda em construção, não poderão suprir as necessidades da reestruturação prevista, e a estratégia ficará provavelmente limitada à tentativa de controle dos canais de venda e dos fornecedores, dando prosseguimento à competição pelo preço.

Desta forma, fica claro que a busca de um design diferenciado, mesmo que não seja ainda parte do cotidiano do polo, é uma necessidade emergente, tornando-se, portanto, essencial para um processo de construção de valor simbólico e de competências. Neste sentido pode haver estimulos de instituições, sob pena de levar os resultados exitosos a um vocabulário inovador e uma diferenciação semântica dos produtos.

\section{Notas}

${ }^{1}$ Informação fornecida por Sandro Ferreira de Souza (gestor do núcleo de design do SENAI em Ubá) em entrevista em Ubá, 31 jul. 2008.

${ }^{2}$ Informação fornecida por Eliane Rossignoli (Gestora do projeto APL e gerente do SEBRAE/Ubá), em entrevista em Ubá: 14 jun. 2009.

${ }^{3}$ Informação fornecida por Eliane Rossignoli. Ubá: 14 jun. 2009.

${ }^{4}$ Informação fornecida por Eliane Rossignoli.Ubá: 14 jun. 2009. 


\section{Referências}

AGÊNCIA SEBRAE DE NOTICIAS. Home page institucional. Apresenta noticias relativas à ação do SEBRAE e às empresas junto as quais atua. Disponível em: <www.agenciasebrae.com.br>. Acesso em: 20 set. 2008.

ALMEIDA, L. B.; MOURA, A. D. Avaliação da estratégia de desverticalização da cadeia moveleira de Ubá (MG) e região sob o enfoque dos modelos de decisão de fazer versus comprar. In: CONGRESSO DA SOCIEDADE BRASILEIRA DE ECONOMIA ESOCIOLOGIA RURAL, 53, 2005, Ribeirão Preto. Anais... Ribeirão Preto: SOBER, 2005. Disponível em: <http://www.sober.org.br/ palestra/2/572.pdf>. Acesso em: 22 jan. 2009.

CENTRO MINAS DESIGN. home page institucional. Apresenta informações sobre programas e ações. Disponível em: <http://www.minasdesign.mg.gov.br>. Acesso em: 12 out. 2008.

CETELEM/IPSOS. Pesquisa aponta consolidação do aumento da classe $C$ e diminuição da desigualdade de renda no país [2008]. Disponível em: <http://www.cetelem.com.br/ portal/elementos/pdf/pdf_press_release2008.1.pdf>. Acesso em: 12 mar. 2009

CROCCO, M.; HORÁCIO, F. Industrialização descentralizada: Sistemas Industriais Locais. Rio de Janeiro: Instituto de Economia da Universidade Federal do Rio de Janeiro, mar. 2001. (Contrato BNDES/FINEP/FUJB. Nota Técnica 38).

DATAFOLHA. Pesquisa mostra ampliação da classe C. jul. 2006. Disponível em: <http://datafolha.folha.uol. com.br/po/ver_po.php?session=255>. Acesso em: 22 jun. 2009.

FEDERAÇÃO DAS INDÚSTRIAS DO ESTADO DE MINAS GERAIS. Diagnóstico do Polo Moveleiro de Ubá e Região. Belo Horizonte: IEL/MG, 2002.

MARÇAL, F. V. et al. Impacto da Metodologia de Projeto de Produto na Qualidade dos Móveis das Empresas Participantes do Projeto Pró-Ubá. In: CONGRESSO DE PESQUISA \& DESENVOLVIMENTO EM DESIGN, 7., 2006, Curitiba, Anais... Curitiba: AEND, 2006. 1 CD-ROM
MORAES, D. Design e identidade local: o território como referência projetual. Os casos dos APLs moveleiros de Ubá e Goiânia. In: CONGRESSO BRASILEIRO DE PESQUISA E DESENVOLVIMENTO EM DESIGN, 8., 2008.São Paulo. Anais... São Paulo: Associação de Ensino e Pesquisa de Nível Superior de Design do Brasil (AEND), 2008. p.1044 a 55.

OLIVEIRA JR, A. Polo Moveleiro de Ubá, MG: instituições, parcerias empresariais e desenvolvimento local; [Sl: s.n], [2005?] (apresentação "Power Point". 10 slides). Disponível em: <ftp://146.164.23.131/redesul/ ANTONIO.pdf>. Acesso em: 22 mai. 2008.

SANTOS, T. C. B.; Internet classe C: padrão de consumo das classes $\mathrm{C}$ e D no Brasil e estratégia de marketing na web. 2007. Monografia (Faculdade de Comunicação) Universidade Federal da Bahia, Salvador, 2007.

SANTOS, F.; CROCCO M.; SIMÕES, R.. Arranjos Produtivos Locais Informais: Uma Análise de componentes principais para Nova Serrana e Ubá Minas Gerais. In: SEMINÁRIO SOBRE A ECONOMIA MINEIRA, 10., 2002, Diamantina. Anais..., Diamantina: UFMG/CEDEPLAR, 2002. p. 1-28. Disponível em: <http://www.cedeplar.ufmg.br/diamantina2002/ textos/D30.PDF>. Acesso em: 02 fev. 2008.

SILVA, A. R. O papel das políticas públicas no desenvolvimento sustentável do Arranjo Produtivo Moveleiro de Ubál MG. 2008. 141 f. Dissertação (Mestrado) - Universidade Federal de Viçosa, Viçosa, 2008. Disponível em: <http:/ /www.ufv.br/>. Acesso em: 22 fev. 2009.

SINDICATOINTERMUNICIPAL DAS INDÚSTRIASDE MARCENARIA DA UBÁ Polo Moveleiro de Ubá. [Ubá]: INTERSIND, [2005?]. Apresentação power point. 20 slides. Disponível em: <http://www.mdic.gov.br/ arquivos/1199709035>. Acesso em: maio 2007.

VALE, G. M. V. Laços como ativos territoriais: Análise das aglomerações produtivas na perspectiva do capital social. 2006. 379 f.. Tese (Doutorado em Administração) Universidade Federal de Lavras, Lavras, 2006.

WRIGHT, P.; KROLL, M. J.; PARNELL, J. Administração estratégica: conceitos. São Paulo: Atlas, 2000. 